\title{
P02-006 - A novel PSTPIP1 mutation in PAPA syndrome
}

\author{
B Fathalla', M Al-Mutawa ${ }^{2}$, F Al-Amri ${ }^{1}$, S Al-Dosari ${ }^{2}$, M Kambouris $^{2}$, H El-Shanti ${ }^{*}$ \\ From 7th Congress of International Society of Systemic Auto-Inflammatory Diseases (ISSAID) \\ Lausanne, Switerland. 22-26 May 2013
}

\section{Introduction}

Pyogenic arthritis, pyoderma gangrenosum, and acne (PAPA) syndrome is an autosomal dominant autoinflammatory disease caused by mutations in the proline-serinethreonine phosphatase-interacting protein 1, PSTPIP1.

The produced protein is a cytoskeleton-associated adaptor protein that modulates T-cell activation, cytoskeletal organization and IL- $1 \beta$ release.

The only two mutations described so far, A230T and E250Q, have been found in patients and families, and are thought to disrupt the binding of PSTPIP1 with PTPPEST, a regulatory phosphatase, and increase its avidity for pyrin in the cytosol, thereby dysregulating IL- $1 \beta$ production. PAPA syndrome typically presents with recurrent sterile, erosive arthritis in childhood, resulting in significant joint destruction. By puberty, joint problems tend to subside and cutaneous symptoms increase including pathergy, frequently with abscesses at the sites of injections, severe cystic acne, and recurrent non-healing sterile ulcers, often diagnosed as pyoderma gangrenosum.

\section{Case Report}

We describe a a four year old Jordanian male, born to healthy non-consanguineous parent, who presented with cutaneous abscesses at the age of 6 months and then at 18 months at the vaccination injection sites. At the age of 20 months he developed cellulitis. At the age of 23 months, he had acute arthritis of the right ankle. He developed acute arthritis of the left wrist at 24 months, and the right wrist at 27 months and then the right elbow at the age of 45 months. He has two older sisters and the family history is negative for similar conditions. The sequencing of the coding region of PSTPIP1 and flanking intronic regions revealed a de novo variation p.Asp246Asn (p.D246N) in the child. The variant is predicted to be probably damaging by

${ }^{2}$ Shafallah Medical Genetics Center, Doha, Qatar

Full list of author information is available at the end of the article
Polyphen and was not found in 360 ethnically-matched control chromosomes.

\section{Discussion}

We describe a 4 year old Jordanian boy with a typical clinical presentation of PAPA syndrome, with the exception of the absence of pyoderma gangrenosum and acne. However, both these findings may occur later in the course of the disease, mostly after puberty. We anticipate that this variation is the mutation the explains the symptoms in this child since it falls within the coiled coil domain that harbors all the previously described mutations. Since the E250Q and A230T variants of PSTPIP1 were shown to severely abrogate binding to PTP-PEST in yeast two hybrid and co-immunoprecipitation experiments, we anticipate this mutation does the same.

\section{Disclosure of interest}

None declared.

\section{Authors' details}

${ }^{1}$ Hamad Medical Corporation, Doha, Qatar. ${ }^{2}$ Shafallah Medical Genetics

Center, Doha, Qatar.

Published: 8 November 2013

\section{References}

1. Wise CA, Gillum JD, Seidman CE, Lindor NM, Veile R, Bashiardes S, Lovett M: Mutations in CD2BP1 disrupt binding to PTP PEST and are responsible for PAPA syndrome, an autoinflammatory disorder. Hum Mol Genet 2002, 11:961-969.

2. Masters SL, Simon A, Aksentijevich I, Kastner DL: Horror autoinflammaticus: the molecular pathophysiology of autoinflammatory disease. Annu Rev Immunol 2009, 27:621-668.

3. Smith EJ, Allantaz F, Bennett L, Zhang D, Gao X, Wood G, Kastner DL, Punaro M, Aksentijevich I, Pascual V, et al: Clinical, Molecular, and Genetic Characteristics of PAPA Syndrome: A Review. Current genomics 2010, 11:519-527.

doi:10.1186/1546-0096-11-S1-A113

Cite this article as: Fathalla et al:: P02-006 - A novel PSTPIP1 mutation in PAPA syndrome. Pediatric Rheumatology 2013 11(Suppl 1):A113.
(C) 2013 Fathalla et al; licensee BioMed Central Ltd. This is an Open Access article distributed under the terms of the Creative Commons Attribution License (http://creativecommons.org/licenses/by/2.0), which permits unrestricted use, distribution, and reproduction in any medium, provided the original work is properly cited. 